\title{
Partial Pressure Arterial Oxygen to Fraction Inspired Oxygen Ratio Measurement
}

National Cancer Institute

\section{Source}

National Cancer Institute. Partial Pressure Arterial Oxygen to Fraction Inspired Oxygen

Ratio Measurement. NCI Thesaurus. Code C119293.

The determination of the ratio of the pressure of oxygen dissolved in arterial blood to the percentage oxygen of an inhaled mixture of gasses in a biological specimen. 